EMPLOYEES AND THE INNOVATIVE IDEA CONTRIBUTION PROCESS

\title{
Employees and the innovative idea contribution process: clarifying individual and contextual characteristics
}

\author{
Natalya Sergeeva \\ School of Construction Management and Engineering, University of Reading, PO Box 219, \\ Reading, RG6 6AW, UK \\ Email: n.sergeeva@reading.ac.uk \\ Telephone: $+44(0)$ 0118-378 5264
}




\title{
EMPLOYEES AND THE INNOVATIVE IDEA CONTRIBUTION PROCESS
}

\begin{abstract}
Understanding how contextual and individual characteristics affect employee willingness to propose innovative ideas to an organization is an important, if understudied aspect of the innovation process. Based on an interactional perspective, widely used in creativity and innovation studies, this paper examines the influence of both contextual and individual characteristics on employee willingness to contribute innovative ideas to other organizational actors. Using a quasi-experimental approach, it is reported that intrinsic motivation, knowledge and curiosity are more important motivators than individual position in the company and any potential financial rewards. Additionally, the personality dimensions of the Big-Five Inventory show no significant affect on employee willingness to contribute ideas. The results of the study are contextualized with the literature regarding the idea contribution processes, and further research directions are indicated.
\end{abstract}

Key words: contextual characteristics, creativity, idea contribution, individual characteristics, innovation 


\section{Employees and the innovative idea contribution process: clarifying individual and contextual characteristics}

\section{Introduction}

Whilst innovative ideas are recognized as potentially originating from inside or outside the organization (e.g. Van de Ven, 1986; Woodman et al., 1993), it has also been noted that employee willingness to propose ideas to other actors can have an impact upon organizational performance and effectiveness (e.g. Morrison, 2011; Takeuchi et al., 2012). Research has indicated that employees can resist contributing ideas to their superiors for different contextual and personal reasons (e.g. Detert and Trevino, 2010). Within organizations, employees make decisions on whether or not to share innovative ideas with various organizational actors. Employees continuously resolve these choices through personal judgements, assessments, thoughts and decisions, having significant implications for organizational innovations. Hence, it has become important to try and understand the conditions that facilitate employee willingness to contribute innovative ideas to other organizational actors. As Tangirala and Ramanujam (2008) state, understanding employee orientations towards the idea contribution process can, arguably, help organizations to promote innovations.

Over the last few years, there has been a growing number of conceptualizations surrounding employee willingness to propose constructive and insightful ideas (e.g. Dutton et al., 2001; Janssen, 2005). However, such constructs have been primarily focused on the supervisor-subordinate relationship. There has been little clarification or improvement in understanding of employee perspectives on proposing innovative ideas to other organizational actors (e.g. team leaders, work colleagues, potential investors, venture or R\&D companies, business partners). Additionally, a growing interest in organizational contexts and 


\section{EMPLOYEES AND THE INNOVATIVE IDEA CONTRIBUTION PROCESS}

how individual characteristics influence employee willingness to propose ideas has been accompanied by a scholarly lack of understanding of what characteristics are more important. Building upon motivation theories and literature on organization citizenship behaviour, Sergeeva and Radosavljevic (2012) conceptualize willingness to contribute ideas as an interface between creativity and innovation influenced by individual and contextual characteristics. These ideas are taken further, building on more recent studies on voice behaviour, silence, issue selling, personal initiatives and interactional perspective widely used in creativity and innovation research. Drawing upon these literature streams, this paper examines the contextual and individual characteristics and their interrelationships associated with employee willingness to contribute ideas to other organizational actors. Particularly, this study examines in detail the influence of expertise, perceived radicality of innovative ideas and the Big-Five personality dimensions on employee willingness to propose ideas to other organizational actors. A clarification of these characteristics can, arguably, contribute to an enhanced understanding of why individuals choose to innovate in a workplace. It can also help in suggesting possible interventions to encourage innovation from an organizational perspective.

In part, this paper responds to a call by Morrison (2011) to investigate the motives for proposing innovative ideas in relation to a target audience. In order to empirically investigate employee willingness to propose ideas to the target audience, a quasi-experimental intervention study was designed and utilized as recommended in the literature (Rank et al., 2004). The paper begins by reviewing existing epistemologies of the employee idea contribution process and goes on to examine the contextual and individual characteristics which influence employee behavior in this sphere. The quasi-experiment is then described and empirical findings are presented, together with a discussion and some implications of the findings. Future research directions are suggested in conclusion. 


\section{EMPLOYEES AND THE INNOVATIVE IDEA CONTRIBUTION PROCESS}

\section{Employee and the idea contribution process}

The important role of employees in the idea contribution process has been recognized for several decades (e.g. Janssen, 2004; Scott and Bruce, 1994; Van de Ven, 1986). Employees can help to accelerate business performance through their ability to generate ideas that improve products, services and work processes. Whilst creativity has been defined as the generation of novel, useful and appropriate ideas (Hennessey and Amabile, 2010), innovation embraces other human behaviors, such as idea expression, idea recognition and idea implementation (Hirst et al., 2009). In organizational contexts, a generated idea can only become an innovation if an individual proposes the idea to actors who make decisions about acceptance and implementation (e.g. Janssen, 2004; Van de Ven et al., 2008). Employee willingness to propose an idea to other organizational actors may be seen as a conceptual mediator between the idea generation and the idea implementation events (e.g. Sergeeva and Radosavljevic, 2012). It is important to note that employees can engage in any combinations of these behaviors over time because innovation is assumed to be a dynamic process that unfolds over time in social contexts (e.g. Scott and Bruce, 1994; Van de Ven et al., 2008). Over the last few years, several concepts surrounding employee willingness to propose ideas to other organizational actors have been developed in the literature: voice behavior, silence, issue selling and personal initiative. These concepts will now be discussed in turn.

Employee voice behavior has been recognized as being closely related to employee willingness to contribute ideas, being defined as the expression of change-oriented ideas, opinions and suggestions about work-related issues with the intention to improve organizational performance (e.g. Morrison, 2011; Ng and Feldman, 2012). In relation to creativity and innovation, Janssen et al. (1998) and Van Dyne et al. (2003) recognize the voicing of ideas as important for solving work-related problems and effective organizational functioning. The voice encompasses communication of ideas, suggestions, challenges, views 


\section{EMPLOYEES AND THE INNOVATIVE IDEA CONTRIBUTION PROCESS}

and opinions. Morrison (2011) distinguishes between three types of voice: suggestionfocused (communication of ideas or suggestions for how to improve the work unit or organization), problem-focused (employee expression of opinions and concerns about work harmful, to the organization) and opinion-focused (communicating opinions on work-related issues that differ from those held by others). Employee willingness to propose ideas is more closely aligned with suggestion-focused voice: sharing innovative ideas with organizational actors to improve or change work-related issues.

Research on employee silence, as opposed to employee voice, is also relevant to employee willingness to contribute ideas. Silence is often defined as withholding of ideas, suggestions or concerns about potential improvements of work-related issues from individuals who might be able to take actions to address those issues (e.g. Van Dyne et al., 2003). There has been less research on silence, rather scholars have primarily focused on predictors of an individual's decision on whether or not to speak up. According to Morrison (2011), the debate on whether silence and voice are distinct or continuum constructs led to the argument that a high level of one results in low a level of the other, and characteristics that predict one also predict the other in opposite direction.

Issue selling is another construct related to employee willingness to contribute ideas. It can be seen as a subset of employee voice that focuses on a particular type of upward communication. Issue selling is often defined as the process by which team members try to get attention from actors higher in the organizational hierarchy to the issues that have implications for organizational performance (e.g. Dutton et al., 2001; Dutton et al., 2002). Whilst issue selling is specifically focused on information about organization-level strategies, employee willingness to contribute ideas concerns proposing change-oriented innovative ideas about work-related issued to other organizational actors. Finally, personal initiative is another related construct, broader than issue selling, voice behavior and, thus, employee 


\section{EMPLOYEES AND THE INNOVATIVE IDEA CONTRIBUTION PROCESS}

willingness to contribute ideas. Personal initiative is often defined as proactive behavior of going substantially beyond the contents of one's job and spending additional time and energy at work (e.g. Frese and Fay, 2001). In order to inform our understanding of employee willingness to propose ideas, the current study draws from each of these literature streams.

The majority of research surrounding employee willingness to contribute ideas has been primarily focused on innovative ideas voiced by subordinate employee to actors higher in the organizational hierarchy, as well as to team leaders (e.g. Burris et al., 2008; Detert and Burris, 2007). Recently, however, Tangirala and Ramanujam (2008) note that employee voice and silence are potentially multi-faceted constructs that might be engaged by different actors, including frontline employees, managers, top-level executives. Employee voice and silence could be directed towards different target audience, including co-workers, superiors and external regulatory agencies. According to Liu et al. (2010), voice is target-sensitive and depends on the person or a group to whom an employee is proposing an innovative idea. For example, an employee might choose to share an innovative idea with business partners, relatives and friends, but not with an immediate superior and work colleagues. Therefore, employee willingness to contribute ideas may depend on target audiences.

Although researchers have shed light upon characteristics that influence employee voice and silence directed to actors higher in the organizational hierarchy, their findings may not necessarily apply to employee voice directed toward other business actors, such as business partners (from other companies), potential investors, venture or R\&D companies (Morrison et al., 2011). This study, therefore, investigates the influence of the contextual and individual characteristics on employee willingness to contribute ideas in relation to these target audiences: direct superiors, team leaders, work colleagues, business partners, potential investors or employers, venture or R\&D companies. 


\section{Individual and contextual characteristics influencing the idea contribution}

\section{process}

The majority of the theoretical and empirical research surrounding employee willingness to propose ideas to other organizational actors has been primarily focused on identifying contextual and individual factors that facilitate or inhibit employee behavior in this sphere. In the domain of creativity research, previous studies (e.g. Amabile et al., 1994; Shalley, 1991) established how behaviors, goal orientations and domain-relevant skills of individuals are intrinsic motivators for innovative contributions. These past investigations revealed that motivational orientation can change, depending on the social contexts in which individuals interact (Amabile, 1996) and their personal characteristics (Hirst et al., 2009). Barron and Harrington (1981), Csikszentmihalyi (1992), Feist (1998) and Furnham et al. (2009) all discovered a positive correlation between creativity and personal factors, including expertise, intrinsic motivation, curiosity, intelligence, self-confidence and personality types. These findings have been reaffirmed by Amabile (1996), Oldham and Cummings (1996) and Shalley et al. (2004) who also identified a positive correlation between creativity and organizational factors, including supervisory encouragement, supportive organizational climate and culture. Although they include flexibility, innovation scholars also revealed a positive correlation between all of these factors and employee innovative behavior (e.g. Bunce and West, 1995; Scott and Bruce, 1994).

Using a person-context interactional perspective, widely mobilized in creativity and innovation studies (e.g. Janssen, 2004; Ramus, 2001; Woodman et al., 1993; Zhou et al., 2009), as well as employee voice behavior research (e.g. Janssen et al., 1998; Morrison, 2011), it can be argued that employee willingness to propose ideas to other organizational actors depends upon interrelated contextual and individual characteristics. On the one hand, contextual characteristics at the team and organizational levels, including collaborative 


\section{EMPLOYEES AND THE INNOVATIVE IDEA CONTRIBUTION PROCESS}

culture and climate, a superior's support and encouragement, individual position in the company and in the team, and financial rewards are assumed to influence employee willingness to contribute ideas to other organizational actors. On the other hand, individual characteristics, including expertise, intrinsic motivation, curiosity, self-confidence, experience, skills and capabilities, personality types and perceived radicality of ideas are also taken into account.

Considering recent theoretical reviews of organizational change (e.g. Weick and Quinn, 1993; Van de Ven et al., 2008), it is likely that employee willingness to contribute high or less radical ideas to other organizational actors has a potential of affecting radical as opposed to incremental forms of innovation. Radicality of innovation has been defined from various perspectives: as a degree of change, novelty, requirements of new information and learning, risk and cost (e.g. Bessant and Tidd, 2007; Damanpour, 1988; Rice et al., 2001; Stüer et al., 2010). A widely used approach is to distinguish between radical and incremental innovations. Incremental innovations are minor changes to existing products, processes or business models, whilst radical innovations represent much more profound changes or entirely new approaches. Interestingly, a recent study by Markard and Truffer (2006) critique the incremental-versus-radical classification as being oversimplified, distinguishing between low, moderate and highly radical innovations. In this case, radicality has been defined as a degree of change and novelty in the existing product. This study adapts Markard and Truffer's (2006) classification of innovative ideas by low, medium and high levels of radicality.

Some employees may have little reservation in proposing highly radical ideas, whilst others would not share these ideas with work colleagues or superiors (e,g. Detert and Trevino, 2010). The required expertise for generating a highly radical idea is likely to be higher than for a low radical idea because the first requires a specialization in relation to the existing product or process. It is also logical to expect that experts are confident to contribute 


\section{EMPLOYEES AND THE INNOVATIVE IDEA CONTRIBUTION PROCESS}

highly radical ideas to organizational actors responsible for making decisions about their acceptance and implementation (e.g. immediate superior, team leader). Non-experts, on the other hand, may be less confident to contribute highly radical ideas to the responsible actors where expertise is essential or may incline towards low or medium radical ideas.

Empirical research also suggests that personality may be related to the idea contribution process. The theory behind the Five-Factor model of personality assumes that individuals vary along five key dimensions: extraversion, agreeableness, consciousness, neuroticism and openness (e.g. McCrate and Costa, 1999). Empirical studies on creativity have investigated the affect of the BFI dimensions on the idea generation process. Furnham et al. (2009), for example, revealed creativity to be positively correlated to extraversion, openness to experience and negatively to agreeableness. Batey et al. (2009), in contrast, discovered that only openness to experience is positively correlated to creativity, whilst there is a negative correlation between neuroticism and creativity. Similar findings span across recent studies on employee voice behaviour. LePine and Van Dyne (2001) identified four of the Big-FiveFactors are differently relevant to employee voice. In particular, extraversion and consciousness have been positively correlated to voice; neuroticism and agreeableness have been negatively correlated to voice, whilst no significant correlation has been revealed between openness to experience and voice. In contrast, Thomas, Whitman, and Viswesvaran (2010) identify a positive correlation between proactivity and extraversion, as well as openness to experience, and no significant correlations to other personality dimensions. The validity of the Big-Five Inventory (BFI) is evident (e.g. John and Naumann, 2010), but the framework has also been questioned (e.g. Paunonen and Jackson, 2000). Consequently, a search for personality traits outside of the BFI can be observed (e.g. Simms et al., 2008).

Employee willingness to contribute ideas to other organizational actors is somewhat conceptually related to the BFI, as it is related to creativity and employee voice. The 


\section{EMPLOYEES AND THE INNOVATIVE IDEA CONTRIBUTION PROCESS}

contradictive results suggest that the BFI may show personality differences in relation to employee willingness to contribute ideas to other organizational actors (e.g. Le Pine and Van Dyne, 2001; Thomas et al., 2010). For example, sociable, active and assertive extraverts are assumed to be more likely to share innovative ideas with various actors in comparison to more quite, reserved and shy introverts. It can also be argued that individuals who tend to be conscientious towards self-discipline, responsibility and self-discipline are more likely to engage in the innovation process than those who are less conscientious. In the similar vein, individuals who are open to new experience, curious and original are assumed to be more innovative and seek new opportunities than those who are less open to novelty. Individuals who are low in neuroticism (e.g. emotionally stable, self-confident) are assumed to actively engage in the innovation process. In contrast, those who are high in neuroticism (e.g. anxiety, depression) are assumed to hesitate proposing innovative ideas. Finally, agreeable individuals, who are associated with value cooperation and conforming with norms, may not be inclined towards proposing innovative ideas to potential actors, but passively accept the existing circumstances (e.g. Le Pine and Van Dyne, 2001; Thomas et al., 2010).

\section{Research design}

It has been recognized in the construction sector that innovations offer the potential for significant organizational and industrial improvements (e.g. Bresnen and Marshall, 2001). However, whilst it is evident that many construction innovations originate from employees, there remains a lack of understanding concerning the contextual and individual characteristics that shape the idea contribution process. Therefore, a research study focusing upon construction sector employee orientations towards the idea contribution process is both valid and valuable. Additionally, in the construction sector there has been a call for more experimental studies into the idea contribution process (e.g. Bernold and Lee, 2010). 


\section{EMPLOYEES AND THE INNOVATIVE IDEA CONTRIBUTION PROCESS}

A variety of building construction professionals, with some expertise of bridge construction, but with little expertise of ship construction, as well as non-construction professionals were invited to participate in a quasi-experimental study. The sample was selected on the basis of expertise differentiations between the construction and nonconstruction professionals. This was necessary in order to investigate the effects of expertise differentiations on the idea contribution process. This differentiation is based on employees' specialization, personal experience and the skills required for building, bridge and ship construction. The non-randomized sample was composed of 76 employees: 38 being from construction companies (the experimental group) and 38 being from non-construction companies, these constituting a control group. At the time of the quasi-experiment, $32 \%$ of participants were senior managers, $27 \%$ were junior/middle managers and the other $41 \%$ were holding non-managerial positions. On average, employees were 31.25 years old and had an organizational tenure of 5.73 years in the UK.

\section{Quasi-experimental tasks}

As the idea generation process can be investigated using a quasi-experimental approach, the study assumed that the idea contribution process can be examined using similar principles. The quasi-experiment took approximately two and a half hours in total to complete. Several employees performed the quasi-experimental tasks at the same time, working individually without sharing their ideas with each other. The quasi-experiment used a series of images of three artifacts: "Taipei 101", "Great Belt East Bridge” and "Queen Mary II”, representing the three different industrial sectors of civil construction, infrastructure construction and ship construction. A visual representation of artifacts is particularly useful in experimental studies for obtaining a better understanding of given information (LeGrand, 1990). These three artifacts were selected according to a set of following equivalence criteria in order to ensure comparatives: 


\section{EMPLOYEES AND THE INNOVATIVE IDEA CONTRIBUTION PROCESS}

- Status equivalence: three artifacts are well known for their superlatives when built, but all of them have since been superseded by other structures making their status equivalent: "Taipei 101" is one of the tallest buildings in the world, "Great Belt East Bridge" is one of the longest bridges in the world and "Queen Mary II" is one of the biggest ships in the world;

- Visual equivalence: three artifacts are shown from three equivalent angles: front view, front view from a distance and lateral view and share the same size and coloring;

- Description equivalence: each artifact is also supported with a textual description of equal length and detail, including general characteristics, technical information, construction technology, superstructure, construction methods and exterior design.

The first quasi-experimental task required employees to generate as many innovative ideas as possible that would either change or improve the three artifacts shown on the images, if they were to start building them from the beginning. Fifteen minutes were given to generate ideas for each of the three artifacts with short breaks in between. This task is operationally similar to the existing experimental study conducted by Sternberg et al. (1997). In their study people had to produce two creative products in each of four domains: writing, art, advertising and science. Three to ten topics were offered and fifteen peers were invited to evaluate people's creativity of the produced products. The findings of the study indicated that people who did well in writing, for example, did not necessarily do well in the other fields. The reason for this domain specificity is the required expertise of the field.

The second quasi-experimental task required employees to evaluate ideas by their radicality and self-report whether they would propose these ideas to other organizational actors. Initially, employees were asked to evaluate their own generated ideas by low, medium and high levels of radicality from the first quasi-experimental task, as well as ideas that were 


\section{EMPLOYEES AND THE INNOVATIVE IDEA CONTRIBUTION PROCESS}

prepared in advance by the researcher. To test the suggested levels of radicality, six ideas were prepared in advance for each artifact, two of which correspond to each of the proposed levels of radicality. Ideas were presented in a random order in terms of their radicality to ensure that employees were unaware of this pre-categorisation. Instead of inviting other peers to evaluate innovative ideas, as conducted by Sternberg et al. (1997), this study focused on employees' own perceptions and opinions. Secondly, employees were asked to select one or more groups of actors to whom they would be willing to propose ideas: an immediate superior, a team leader, or work colleagues. These were selected because they are related to an employee's work and are often involved in the decision-making process and starting the implementation process (Van de Ven et al., 2008). This was contrasted with a secondary group, comprising business partners (from other companies), potential investors, venture or R\&D companies, professionals (e.g. famous architects, academics, chief executive officers), friends (not from work) and relatives who may not be directly involved in any decision making processes.

Questionnaires were completed at different stages during the quasi-experimental procedure. The first questionnaire included general background information and work experience which was introduced before the quasi-experimental tasks. The second questionnaire was introduced after the quasi-experimental tasks and was directly related to employees' evaluations of contextual and individual characteristics perceived to be important for willingness to propose ideas to other organizational actors. This questionnaire was designed to assess the intrinsic reasons why employees are willing to contribute innovative ideas to other organizational actors. The third questionnaire included the BFI personality inventory which was introduced at the very end of the task. Employees were differentiated by the BFI personality dimensions (John et al., 2008). Using the BFI enables an investigation of the differences in the numbers of proposed ideas by individuals of different personality 


\section{EMPLOYEES AND THE INNOVATIVE IDEA CONTRIBUTION PROCESS}

dimensions and their effect on employee willingness to contribute ideas. In this particular case, the main role of the BFI is not to distinguish various personalities per se, but rather to elicit personality dimensions in order to determine differences in the number of proposed ideas.

\section{Analysis}

Individual and contextual characteristics influencing employee willingness to contribute ideas

It is commonly understood that creative output, intentions and motivation can be investigated qualitatively (e.g. novelty, value of ideas evaluated by judges) and quantitatively (the number of ideas). While there have been a number of studies using the first approach (e.g. Kristensson et al., 2004; Sternberg et al., 1997), the latter has been also utilised frequently (e.g. MacCrimmon and Wagner, 1994; Wierenga and Van Bruggen, 1998). In this study employee willingness to contribute ideas is measured as the number of proposed ideas to other organizational actors. Descriptive statistics and correlation analysis have been performed using SPSS software. The three-dimensional measurement of employee willingness to contribute ideas (number of ideas, novelty and value) could become a new research direction.

Table 1 presents the means, standard deviations, correlations and scale reliability of the variables (contextual and individual characteristics) that employees evaluate as important for willingness to contribute ideas to other organizational actors based on a five-point Likert-type scale ranging from 1 ("least important") to 5 (“most important").

Insert Table 1 about here 


\section{EMPLOYEES AND THE INNOVATIVE IDEA CONTRIBUTION PROCESS}

On average, individual characteristics have been evaluated as more important than contextual characteristics by employees in relation to their willingness to contribute ideas to other organizational actors. In particular, expertise, intrinsic motivation, skills and capabilities, and curiosity have been identified to be more important for employee willingness to contribute ideas than financial rewards, position in the company and in the working team. The correlation analysis has shown that the majority of contextual and individual characteristics are significantly interrelated. For example, curiosity is positively correlated to intrinsic motivation $(\mathrm{r}=.65, \mathrm{p}<0.01)$; self-confidence is positively correlated to financial rewards $(\mathrm{r}=.28, \mathrm{p}<0.01)$.

\section{Expertise, perceived radicality influencing employee willingness to contribute ideas}

Table 2 presents percentages of proposed ideas by employees to other organizational actors by levels of radicality and three artifacts. The results reveal a clear difference between construction and non-construction employees in relation to levels of radicality for the three artifacts.

Insert Table 2 about here

Construction professionals showed a greater percentage of proposed high radical ideas to all actors than low and medium. In contrast, non-construction professionals principally resorted to proposing ideas of low and medium radicality, with an exception of business partners where they contributed a greater number of ideas. The results for the bridge artifact revealed that construction professionals were more cautious regarding the proposed high radical ideas. They were intended to propose more ideas of medium radicality and to people within their working environment. In this particular case, non-construction professionals shied away from business partners, but the distribution in regards to idea radicality levels is 


\section{EMPLOYEES AND THE INNOVATIVE IDEA CONTRIBUTION PROCESS}

still in favor of low radicality. The results for the ship artifact showed that construction professionals predominantly proposed ideas of low or medium radicality. Interestingly, nonconstruction professionals were slightly more radical in this particular case, but overall, the percentage of proposed ideas appears to increase with expertise and levels of radicality.

\section{The BFI personality dimensions influencing employee willingness to contribute ideas}

Table 3 presents percentages of proposed ideas to other organizational actors distributed by employees’ BFI personality dimensions for three artifacts.

Insert Table 3 about here

On average, employees with high extraversion, neuroticism and openness scores, and with low agreeableness and conscientiousness scores generated greater number of ideas than employees with low extraversion, neuroticism and openness scores, and high agreeableness and conscientiousness scores. These findings are evident across all three artifacts. In relation to the number of proposed ideas to other organizational actors, the results reveal diverse results. The most evident differences across all three artifacts were discovered for employees with high extraversion scores, proposing greater number of ideas to friends and relatives, potential investors, immediate superiors and work colleagues than employees with low extraversion scores. Employees with high openness to experience proposed greater number of ideas to work colleagues, team leader and potential investors than employees with low openness scores. Some further correlation analysis was conducted.

Table 4 presents means, standard deviations and correlations among the employees' BFI personality dimensions for the ship artefact where expertise differentiation between construction and non-construction employees is absent. 


\section{EMPLOYEES AND THE INNOVATIVE IDEA CONTRIBUTION PROCESS}

Insert Table 4 about here

The results identified only few positive correlations between personality dimensions and the percentage of proposed ideas to other organizational actors. For example, the number of proposed ideas to potential investors appears to increase with extraversion scores. The number of proposed ideas to professionals appears to increase with agreeableness and consciousness scores. The number of proposed ideas to business partner appears to increase with openness to experience scores. No other significant correlations, however, were exposed between the BFI personality dimensions and the number of proposed ideas to all other actors.

\section{Discussion}

The paper indicates that, on average, both contextual and individual characteristics are considered to be important in relation to employee willingness to contribute ideas to other organizational actors. Personality-related characteristics, however, emerged with higher values than contextual characteristics. These findings are consistent with the work of Axtell et al. (2000) and Bunce and West (1995) who claimed that individual innovation relies more heavily on individual than perceived group and organizational factors. Significant correlations between the contextual and individual characteristics have been revealed, consistent with an interactional perspective, widely used in creativity and innovation studies (e.g. Janssen, 2004; Woodman et al., 1993; Zhou et al., 2009). The current paper extended the analysis of the data presented by Sergeeva and Radosavljevic (2012), conducting correlations and scale reliability tests in order to examine the interrelationships between the individual and contextual characteristics.

The results showed that the decision to contribute ideas depends upon relevant expertise and the perceived radicality of ideas. In particular, experts were more willing to contribute highly radical ideas than less radical ideas. Non-experts, on the other hand, were 


\section{EMPLOYEES AND THE INNOVATIVE IDEA CONTRIBUTION PROCESS}

more inclined towards proposing low to medium level of radicality of ideas. Thus, organizations clearly require engagement of experts to increase contribution of highly radical ideas with an ultimate goal of achieving radical innovation. Of particular note, the idea contribution process depends upon to whom an employee contributes an innovative idea. The study revealed that to some extent experts were more willing to propose innovative ideas to actors within their work environment (e.g. team leader, work colleagues) than to actors outside the organization (e.g. business partner, potential investors). Thus, those organizations promoting open innovations would, arguably, pay greater attention to collaborations of experts with business partners from other companies, venture or R\&D companies.

Perhaps surprisingly, only few significant correlations between Big-Five personality dimensions and employee willingness to contribute ideas to other organizational actors were revealed, which is different to previous studies on creativity and employee voice (e.g. LePine and Van Dyne, 2001; Furnham et al., 2009; Thomas et al., 2010). It is difficult to generalize from these results, but nevertheless, some correlations were significant between the number of proposed ideas to organizational actors and personality dimensions. Extraverts were more willing to propose ideas to potential investors in comparison to introverts. This is consistent with the associated characteristics of extraverts as being sociable and active personalities (e.g. Thomas et al., 2010). Employees with high openness to experience scores were more willing to contribute ideas to business partners than those with low scores. This is consistent with the associated characteristics of individuals who are open to new experience as being original and curious. Individuals with high conscientious scores were more willing to contribute innovative ideas to professionals than peers with low scores. This is consistent with the associated characteristics of conscientious individuals as being responsible and selfdisciplined. Personality characteristics are, therefore, arguably, critical for the idea contribution process in relation to a target audience. 


\section{EMPLOYEES AND THE INNOVATIVE IDEA CONTRIBUTION PROCESS}

One of the implications of these findings is that efforts to enhance the idea contribution process at work should, perhaps, focus on increasing individual willingness to innovate. This requires paying attention to personal development, enhanced expertise, skills and capabilities. Consequently, this requires altering environmental contingencies, such as rewards associated with successful innovative ideas, fostering collaborative team culture and further organizational encouragements.

\section{Summary and future research directions}

There has been a growing interest within the literature regarding employee willingness to contribute ideas to other organizational actors. This paper examined employees' own perspectives into the issue of whether or not to propose innovative ideas, depending on various contextual and personal reasons. Empirical evidence, such as that reported, can help organizations to better understand the underlying mechanisms of the innovation process. Further research may expand understanding of employee willingness to contribute ideas to other organizational actors from other perspectives, at different contexts, using different methodologies.

The validity evidence associated with the modern constructs of employee voice, silence, issue selling and proactivity is somewhat limited because an interest in these orientations has emerged only relatively recently. Consequently, the sample and measurements included within the analysis limit the conclusions that can be drawn from this preliminary empirical study. The small sample size is due to a selected quasi-experimental design, engaging each individual for a considerable amount of time. Since most experimental studies on human behavior, personality and social psychology use a minimum of thirty participants to get stable measures (Field, 2009), the selected sample is of appropriate size to provide this preliminary empirical integration. It is important to recognize that using an experimental research approach underestimates the impact of contextual characteristics on the 


\section{EMPLOYEES AND THE INNOVATIVE IDEA CONTRIBUTION PROCESS}

idea contribution process. Characteristics such as the perceived radicality of ideas, potential financial rewards and individual position in the company, although potentially significant, do not capture the overall organizational context through an experimental approach. Other contextual factors like recent organizational events, internal politics, financial capabilities and appetite for risks can play a role in whether employees choose to propose an idea (e.g. Bessant and Tidd, 2007). Such factors could be captured through more contextually grounded work, for example, ethnographical studies or action research.

Another limitation is that only the BFI was used to investigate the effects of personality dimensions on the idea contribution process. Future research may investigate this using larger samples and complementary personality inventories (e.g. NEO Five-Factor Inventory). Future research may also investigate BFI in relation to employee willingness to propose low, medium and highly radical ideas in relation to a target audience. Due to the small sample and limited number of proposed ideas, it was impossible to conduct this analysis. The radicality construct should receive greater attention in the future and, perhaps, more than three levels of radicality would be needed. Finally, it is important to note that other individual characteristics like self-esteem, need for achievement, communication could also potentially influence employee willingness to propose ideas to various target audience. The above suggested directions are neither exhaustive nor prescriptive, but they may lead to a more adequate portrayal of employee willingness to propose ideas and how it emerges and evolves in various organizational contexts. 


\section{EMPLOYEES AND THE INNOVATIVE IDEA CONTRIBUTION PROCESS}

\section{References}

Amabile, TM (1996). Creativity in context. Boulder, USA: Westview Press.

Amabile, TM., KG Hill, BA Hennessey and E Tighe (1994). The Work Preference Inventory: Assessing intrinsic and extrinsic motivational orientations. Journal of Personality and Social Psychology, 66(5), 950-967.

Axtell, CM, DJ Homan, KL Unsworth, TD Wall and PE Waterson (2000). Shopfloor innovation: Facilitating the suggestion and implementation of ideas. Journal of Occupational and Organisational Psychology, 73(3), 265-285.

Barron, F, and D Harrington (1981). Creativity, intelligence, and personality. Annual Review of Psychology, 32, 439-476.

Batey, M, Y Chamorro-Premuzik and A Furnham (2009). Intelligence and personality as predictors of divergent thinking: the role of general, fluid and crystallized intelligence. Thinking Skills and Creativity, 4(1), 60-69.

Bernold, LE and TS Lee (2010). Experimental research in construction. Journal of Construction Engineering and Management, 136(1), 26-35.

Bessant, J and J Tidd (2007). Innovation and entrepreneurship. West Sussex, UK: John Wiley \& Sons Ltd.

Block, J (1995). A contrarian view of the five-factor approach to personality description. Psychological Bulletin, 117(2), 187-215.

Bresnen, $\mathrm{M}$ and $\mathrm{N}$ Marshall (2001). Understanding the diffusion and application of new management ideas in construction. Engineering, Construction and Architectural Management, 8(5/6), 335-345.

Bunce, D and MAWest (1995). Self Perceptions and Perceptions of Group Climate as Predictors of Individual Innovation at Work. Applied Psychology: An International Review, 44(3), 199-215. 


\section{EMPLOYEES AND THE INNOVATIVE IDEA CONTRIBUTION PROCESS}

Burris, ER, JR Detert and DS Chiaburu (2008). Quitting before leaving: The mediating effects of psychological attachment and detachment on voice. Journal of Applied Psychology, 93(4), 912-922.

Csikszentmihalyi, M (1992). Motivation and creativity. In R. S. Albert (Eds.), Genius and eminence (pp. 19-33). Oxford, UK: Pergamon Press.

Damanpour, F (1988). Innovation type, radicalness, and the adoption process. Communication Research, 15(5), 545-567.

Detert, JR and ER Burris (2007). Leadership behavior and employee voice: Is the door really open? Academy of Management Journal, 50(4), 869-884.

Detert, JR and LK Trevino (2010). Speaking up to higher-ups: How supervisors and skiplevel leaders influence employee voice. Organization Science, 21(1), 249-270.

Dutton, JE, SJ Ashford, KA Lawrence and K Miner-Rubino (2002). Red light, green light: Making sense of the organizational context for issue selling. Organization Science, 13(4), 335-369.

Dutton, JE, SJ Ashford, RM O’Neill and KA Lawrence (2001). Moves that matter: Issue selling and organizational change. Academy of Management Journal, 44(4), 716-736.

Field, A. (2009). Discovering statistics using SPSS. London, UK: Sage Publications.

Frese, M and D Fay (2001). Personal initiative: an active performance concept for work in the $21^{\text {st }}$ century. Research in Organizational Behaviour, 23(1), 133-187.

Furnham, A, J Crump, M Batey and T Chamorro-Premuzik (2009). Personality and ability predictors of the "consequences" test of divergent thinking in a large non-student sample. Personality and Individual Differences, 46(4), 536-540.

Hennessey, BA and TM Amabile (2010). Creativity. Annual Review of Psychology, 61, 569598. 


\section{EMPLOYEES AND THE INNOVATIVE IDEA CONTRIBUTION PROCESS}

Hirst, G, D Van Knippenberg and J Zhou (2009). A cross-level perspective on employee creativity: Goal orientation, team learning behavior, and individual creativity. Academy of Management Journal, 52(2), 280-293.

Janssen, O (2004). How fairness perceptions make innovative behaviour more or less stressful. Journal of Organizational Behavior, 25(2), 201-215.

Janssen, O (2005). The joint impact of perceived influence and supervisor supportiveness on employee innovative behaviour. Journal of Occupational and Organizational Psychology, 78(4), 573-579.

Janssen, O, T de Vries and AJ Cozijnsen (1998). Voicing by Adapting and Innovating employees: An empirical study on how personality and environment interact to affect voice behavior. Human Relations, 51(7), 945-967.

Janssen, O, E Van de Vliert and M West (2004). The bright and dark sides of individual and group innovation: A special issue introduction. Journal of Organizational Behavior, 25(2), 129-145.

John, OP and LP Naumann (2010). Surviving two critiques by block? The resilient Big Five have emerged as the paradigm for personality trait psychology. Psychological Inquiry, 21(1), 44-49.

John, OP, LP Naumann and CJ Soto (2008). Paradigm shift to the integrative Big Five trait taxonomy: History, measurement, and conceptual issues. In OP John, RW Robins and L A Pervin (Eds.), Handbook of personality: Theory and research. New York, USA: Guilford Press.

Kanter, RM (1983). The change masters. London: Cox \& Wyman Ltd.

Kristensson, P, A Gustafsson and T Archer (2004). Harnessing the creative potential among users. Journal of Product Innovation Management, 21(1), 4-14. 


\section{EMPLOYEES AND THE INNOVATIVE IDEA CONTRIBUTION PROCESS}

LeGrand, HE (1990). Experimental inquiries: Historical, philosophical, and social studies of experimentation in science. Dordrecht, Netherlands: Kluwer Academic Publishers.

LePine, JA and L Van Dyne (1998). Predicting voice behavior in work groups. Journal of Applied Psychology, 83(6), 853-868.

LePine, JA and L Van Dyne (2001). Voice and cooperative behavior as contrasting forms of contextual performance: Evidence of differential relationships with Big Five personality characteristics and cognitive ability. Journal of Applied Psychology, 86(2), 326-336.

Liu, W, R Zhu and Y Yang (2010). I warn you because I like you: Voice behavior, employee identification, and transformational leadership. Leadership Quarterly, 21(1), 189-202.

Luhmann, N (1990). Essays on self-reference. New York, USA: Columbia University Press.

MacCrimmon, KR and C Wagner (1994). Stimulating ideas through creativity software. Management Science, 40(11), 1514-1532.

Markard, J and B Truffer (2008). Technological innovation systems and the multi-level perspective: Towards an integrated framework. Research Policy, 37(4), 596-615.

McCrate, RR and PT Costa (1999). A Five-Factor Theory of personality. In LA Pervin and OP John (Eds.), Handbook of personality (pp. 139-153). New York, USA: The Guilford. Morrison, EW (2011). Employee voice behavior: Integration and directions for future research. The Academy of Management Annals, 5(1), 373-412.

Morrison, EW, SL Wheeler-Smith and D Kamdar (2011). Speaking up in groups: A crosslevel study of group voice climate and voice. Journal of Applied Psychology, 96(1), 183191.

Newton, N (1996). Foundations of understanding (advances in consciousness research). Amsterdam, Netherlands: John Benjamins. 


\section{EMPLOYEES AND THE INNOVATIVE IDEA CONTRIBUTION PROCESS}

Ng, WH and DC Feldman (2012). Employee voice behavior: A meta-analytic test of the conservation of resource framework. Journal of Organizational Behavior, 33(2), 216234.

Oldham, GR and A Cummings (1996). Employee creativity: Personal and contextual factors at work. Academy of Management Journal, 39(3), 607-634.

Paunonen, SV and DN Jackson (2000). What is beyond the Big Five? Plenty! Journal of Personality, 68(5), 821-835.

Ramus, CA (2001). Organizational support for employees: Encouraging creative ideas for environmental sustainability. California Management Review, 43(3), 85-103.

Rank, J, VL Pace and M Frese (2004). Three avenues for future research on creativity, innovation, and initiative. Applied Psychology: An International Review, 53(4), 518-528.

Rice, MP, D Kelley, L Peters and GC O’Connor (2001). Radical innovation: Triggering initiation of opportunity recognition and evaluation. $R \& D$ Management, 31(4), 409-420.

Scott, SG and RA Bruce (1994). Characteristics of innovative behavior: A path model of individual innovation in the workplace. Academy of Management Journal, 37(3), 580607.

Sergeeva, N and M Radosavljevic (2012). Creative participation in construction firms: Bridging creativity and innovation. Organization, Technology and Management in Construction: An International Journal, 4(2), 490-506.

Shalley, CE (1991). Effects of productivity goals, creativity goals, and personal discretion on individual creativity. Journal of Applied Psychology, 76(2), 179-185.

Shalley, CE, J Zhou and GR Oldham (2004). The effects of personal and contextual characteristics on creativity: Where should we go from here? Journal of Management, 30(6), 933-958. 


\section{EMPLOYEES AND THE INNOVATIVE IDEA CONTRIBUTION PROCESS}

Simms, LJ, T Yufik, JP Thomas and EN Simms (2008). Exploring the nature of evaluative person descriptors through scale development. Journal of Research in Personality, 42(5), $1271-1284$.

Sternberg, RJ, LA O'Hara and TL Lubart (1997). Creativity as investment. California Management Review, 40(1), 8-21.

Stüer, C, S Hüsig and S Biala (2010). Integrating art as a trans-boundary element in a radical innovation framework. $R \& D$ Management, 40(1), 10-18.

Takeuchi, R, Z Chen and SY Cheung (2012). Applying uncertainty management theory to employee voice behavior: An integrative investigation. Personnel Psychology, 65(2), 283-323.

Tangirala, S and R Ramanujam (2008). Exploring nonlinearity in employee voice: The effects of personal control and organizational identification. Academy of Management Journal, 51(6), 1189-1203.

Thomas, JP, DS Whitman and C Viswesvaran (2010). Employee proactivity in organizations: A comparative meta-analysis of emergent proactive constructs. Journal of Occupational and Organizational Psychology, 83(2), 275-300.

Van Dyne, L, S Ang and IC Botero (2003). Conceptualizing employee silence and employee voice as multidimensional constructs. Journal of Management Studies, 40(4), 1359-1392.

Van de Ven, AH, DE Polley, R Garud and S Venkataraman (2008). The innovation journey. New York, USA: Oxford University Press.

Weick, KE and RE Quinn (1999). Organizational change and development. Annual Review of Psychology, 50(1), 361-386.

Wierenga, B and GH Van Bruggen (1998). The dependent variable in research into the effects of creativity support systems: Quality and Quantity of ideas. MIS Quarterly, $22(1), 81-87$. 


\section{EMPLOYEES AND THE INNOVATIVE IDEA CONTRIBUTION PROCESS}

Woodman, RW, JD Sawyer and RW Griffin (1993). Toward a theory of organizational creativity. Academy of Management Review, 18(2), 293-321.

Zhou, J, SJ Shin, DJ Brass, J Choi and ZX Zhang (2009). Social networks, personal values, and creativity: Evidence for curvilinear and interactive effects. Journal of Applied Psychology, 94(6), 1544-1552. 


\section{EMPLOYEES AND INNOVATIVE IDEA CONTRIBUTION PROCESS}

Table 1. Means, standard deviations and Kendall's tau correlations among the variables ${ }^{\mathrm{a}}$

\begin{tabular}{|c|c|c|c|c|c|c|c|c|c|c|c|c|c|c|}
\hline Variable & Mean & S.D. & 1 & 2 & 3 & 4 & 5 & 6 & 7 & 8 & 9 & 10 & 11 & 12 \\
\hline (1) Expertise related to an idea & 4.18 & .89 & .82 & & & & & & & & & & & \\
\hline (2) Intrinsic motivation & 4.17 & .77 & $.51 * *$ & .81 & & & & & & & & & & \\
\hline (3) Overall skills and capabilities & 4.07 & .84 & $.39 *$ & $.22 *$ & .82 & & & & & & & & & \\
\hline (4) Curiosity & 4.04 & .84 & $.65 * *$ & $.53 * *$ & $.44^{*}$ & .82 & & & & & & & & \\
\hline (5) Self-confidence and belief in success & 4.00 & .91 & $.40 * *$ & $.44 * *$ & $.40^{*}$ & $.37 * *$ & .81 & & & & & & & \\
\hline (6) Collaborative team culture & 3.84 & .98 & $.22 *$ & $.36^{* *}$ & $.33^{*}$ & $.25^{*}$ & .20 & .82 & & & & & & \\
\hline (7) Experience & 3.83 & .90 & $.35 * *$ & $.42 * *$ & $.35^{*}$ & $.32 * *$ & $.60 * *$ & .11 & .81 & & & & & \\
\hline (8) Superior's support & 3.57 & 1.09 & -.92 & $.24 *$ & .15 & .09 & .08 & $.25^{*}$ & .02 & .84 & & & & \\
\hline (9) Position in a team & 3.38 & 1.08 & -.044 & $.21 *$ & .14 & .06 & $.29 * *$ & $.20 *$ & $.25 *$ & $.26^{* *}$ & .82 & & & \\
\hline (10) Degree of radicality of ideas & 3.31 & .84 & $.25^{*}$ & $.45^{* *}$ & .13 & $.24 *$ & $.22 *$ & $.33 * *$ & $.27 * *$ & .15 & .47 & .81 & & \\
\hline (11) Position in the company & 3.20 & 1.06 & -.00 & $.28 * *$ & .17 & .05 & $.34 * *$ & $.25 * *$ & $.47 * *$ & $.21 *$ & $.61 * *$ & $.38 * *$ & .81 & \\
\hline (12) Financial rewards & 3.01 & 1.34 & .03 & $.26 * *$ & .08 & -.05 & $.28 * *$ & .13 & $.24 *$ & .15 & $.29 * *$ & $.37 * *$ & $.44 * *$ & .83 \\
\hline
\end{tabular}

${ }^{\mathrm{a}} \mathrm{N}=76$

$* \mathrm{p}<0.05$

$* * \mathrm{p}<0.01$.

Cronbach alphas are reported in the diagonal. 


\section{EMPLOYEES AND INNOVATIVE IDEA CONTRIBUTION PROCESS}

Table 2. The percentage of proposed low, medium and high radical ideas ${ }^{\mathrm{a}}$ to other organizational actors by construction and non-construction (in brackets) professionals for building, bridge and ship artifacts

\begin{tabular}{|c|c|c|c|c|c|c|c|}
\hline \multirow{2}{*}{$\begin{array}{l}\text { Radicality of } \\
\text { ideas }\end{array}$} & \multicolumn{7}{|c|}{ Building } \\
\hline & Friends /relatives & Work colleagues & Team leader & Immediate superior & Business partner & Professionals & Potential investors \\
\hline low radical & $1(6)$ & $2(7)$ & $3(6)$ & $2(5)$ & $2(15)$ & $2(5)$ & $2(4)$ \\
\hline medium radical & $3(4)$ & $6(5)$ & $7(4)$ & $6(3)$ & $4(10)$ & $6(3)$ & $6(3)$ \\
\hline high radical & $4(2)$ & $8(3)$ & $9(3)$ & $7(2)$ & $6(6)$ & $7(2)$ & $7(2)$ \\
\hline \multirow[t]{2}{*}{ Average } & $8(12)$ & $16(15)$ & $19(13)$ & $15(10)$ & $12(31)$ & $15(10)$ & $15(9)$ \\
\hline & \multicolumn{7}{|c|}{ Bridge } \\
\hline low radical & $3(2)$ & $5(2)$ & $5(2)$ & $4(2)$ & $2(1)$ & $4(2)$ & $3(1)$ \\
\hline medium radical & $5(8)$ & $9(8)$ & $9(6)$ & $7(6)$ & $4(4)$ & $8(4)$ & $6(3)$ \\
\hline high radical & $3(10)$ & $5(9)$ & $5(8)$ & $4(7)$ & $2(4)$ & $5(6)$ & $3(5)$ \\
\hline \multirow[t]{2}{*}{ Average } & $11(20)$ & 19(19) & $19(16)$ & $14(15)$ & $8(9)$ & $17(12)$ & $12(9)$ \\
\hline & \multicolumn{7}{|c|}{ Ship } \\
\hline low radical & $5(6)$ & $8(8)$ & $8(5)$ & $7(5)$ & $3(3)$ & $6(4)$ & $4(5)$ \\
\hline medium radical & $5(8)$ & $7(11)$ & $7(7)$ & $7(7)$ & $3(5)$ & $6(6)$ & $4(7)$ \\
\hline high radical & $2(2)$ & $4(3)$ & $4(2)$ & $4(1)$ & $2(1)$ & $3(2)$ & $2(2)$ \\
\hline Average & $12(16)$ & $19(22)$ & $19(14)$ & $18(13)$ & $7(9)$ & $15(12)$ & $10(14)$ \\
\hline
\end{tabular}

${ }^{a}$ one idea could be proposed to several actors. 


\section{EMPLOYEES AND INNOVATIVE IDEA CONTRIBUTION PROCESS}

Table 3. The percentage of proposed ideas ${ }^{\text {a }}$ to potential actors distributed by all employees' BFI personality dimensions (below the average score, above the average score in brackets) for three artifacts ${ }^{b}$

\begin{tabular}{|c|c|c|c|c|c|c|c|c|}
\hline \multirow[b]{2}{*}{ BFI dimensions } & \multicolumn{8}{|c|}{ Building } \\
\hline & $\begin{array}{l}\text { Friends } \\
\text { /relatives }\end{array}$ & Work colleagues & Team leader & $\begin{array}{l}\text { Immediate } \\
\text { superior }\end{array}$ & $\begin{array}{c}\text { Business } \\
\text { partner }\end{array}$ & Professionals & $\begin{array}{l}\text { Potential } \\
\text { investors }\end{array}$ & $\begin{array}{c}\text { Average } \\
\text { numbers of } \\
\text { generated ideas } \\
\text { per person }\end{array}$ \\
\hline Extraversion & $9.00(13.79)$ & $17.25(14.73)$ & $15.75(17.87)$ & $13.50(14.73)$ & $18.75(10.03)$ & $14.00(13.48)$ & $11.75(15.36)$ & $2.34(3.38)$ \\
\hline Agreeableness & $10.53(26.92)$ & $15.87(23.08)$ & $16.88(11.54)$ & $14.29(7.69)$ & $15.01(11.54)$ & $13.85(11.54)$ & $13.56(7.69)$ & $2.27(4.33)$ \\
\hline Consciousness & $12.14(4.95)$ & $16.18(15.84)$ & $16.99(14.85)$ & $14.24(12.87)$ & $12.14(31.68)$ & $14.72(7.92)$ & $13.59(11.88)$ & $2.32(2.63)$ \\
\hline Neuroticism & $10.31(11.60)$ & $16.03(16.19)$ & $18.32(17.75)$ & $14.50(13.79)$ & $16.41(14.00)$ & $11.07(15.32)$ & $13.36(13.35)$ & $2.27(2.40)$ \\
\hline \multirow[t]{2}{*}{ Openness } & $10.30(13.64)$ & $15.17(19.89)$ & $15.54(20.45)$ & $14.61(11.93)$ & $17.79(6.25)$ & $14.04(12.50)$ & $12.55(15.34)$ & $2.37(2.32)$ \\
\hline & \multicolumn{8}{|c|}{ Bridge } \\
\hline Extraversion & $14.57(16.54)$ & $21.43(18.11)$ & $15.71(18.50)$ & $13.43(15.75)$ & $9.71(5.51)$ & $14.57(14.17)$ & $10.57(11.42)$ & $2.32(1.88)$ \\
\hline Agreeableness & $15.60(0.00)$ & $19.80(37.50)$ & $16.95(12.50)$ & $14.43(12.50)$ & $8.05(0.00)$ & $14.26(25.00)$ & $10.91(12.50)$ & $1.82(1.83)$ \\
\hline Consciousness & $15.53(14.47)$ & $20.45(17.11)$ & $17.23(14.47)$ & $14.39(14.47)$ & $7.01(14.47)$ & $14.77(11.84)$ & $10.61(13.16)$ & $2.03(3.00)$ \\
\hline Neuroticism & $14.40(16.07)$ & $17.28(21.88)$ & $18.11(16.07)$ & $14.81(14.13)$ & $8.64(7.48)$ & $13.99(14.68)$ & $12.76(9.70)$ & $2.38(2.00)$ \\
\hline \multirow[t]{2}{*}{ Openness } & $15.40(15.38)$ & $19.62(21.54)$ & $16.03(20.00)$ & $15.40(10.77)$ & $8.65(5.38)$ & $14.14(15.38)$ & $10.76(11.54)$ & $2.14(2.11)$ \\
\hline & \multicolumn{8}{|c|}{ Ship } \\
\hline Extraversion & $12.31(15.89)$ & $21.64(18.69)$ & $17.54(16.82)$ & $14.55(15.89)$ & $8.96(7.48)$ & $14.55(12.62)$ & $10.45(12.62)$ & $1.86(1.72)$ \\
\hline Agreeableness & $14.05(0.00)$ & $20.13(40.00)$ & $17.40(0.00)$ & $15.09(20.00)$ & $8.39(0.00)$ & $13.63(20.00)$ & $11.32(20.00)$ & $1.82(1.33)$ \\
\hline Consciousness & $13.86(14.10)$ & $20.79(17.95)$ & $17.33(16.67)$ & $14.85(16.67)$ & $7.43(12.82)$ & $14.36(10.26)$ & $11.39(11.54)$ & $1.72(2.50)$ \\
\hline Neuroticism & $13.47(14.19)$ & $19.17(21.11)$ & $20.21(15.22)$ & $17.10(13.84)$ & $7.77(8.65)$ & $11.40(15.22)$ & $10.88(11.76)$ & $2.00(1.70)$ \\
\hline Openness & $14.40(12.15)$ & $23.36(19.47)$ & $15.47(23.36)$ & $15.47(14.02)$ & $9.60(3.74)$ & $14.40(11.21)$ & $11.20(12.15)$ & $1.82(1.74)$ \\
\hline
\end{tabular}

${ }^{a}$ one idea could be proposed to several actors.

${ }^{\mathrm{b}} \mathrm{N}=76$ 


\section{EMPLOYEES AND INNOVATIVE IDEA CONTRIBUTION PROCESS}

Table 4. Means, standard deviations and Kendall's tau correlations among the BFI dimensions for ship artifact ${ }^{\mathrm{a}}$

\begin{tabular}{|c|c|c|c|c|c|c|c|c|c|}
\hline \multirow[b]{2}{*}{ BFI dimensions } & \multicolumn{9}{|c|}{ Ship } \\
\hline & Mean & S.D. & $\begin{array}{c}\text { Friends } \\
\text { /relatives }\end{array}$ & $\begin{array}{c}\text { Work } \\
\text { colleagues }\end{array}$ & Team leader & $\begin{array}{l}\text { Immediate } \\
\text { superior }\end{array}$ & $\begin{array}{c}\text { Business } \\
\text { partner }\end{array}$ & Professionals & $\begin{array}{l}\text { Potential } \\
\text { investors }\end{array}$ \\
\hline Extraversion & 3.18 & .53 & -.083 & .032 & -.07 & -.128 & -.02 & -.07 & $-.18^{*}$ \\
\hline Agreeableness & 3.91 & .49 & $.184^{*}$ & .071 & .15 & .073 & .09 & $.24^{* *}$ & .13 \\
\hline Consciousness & 3.67 & .53 & .080 & .010 & .02 & .01 & -.13 & $.20^{*}$ & -.00 \\
\hline Neuroticism & 2.84 & .62 & .141 & .071 & .13 & .12 & .161 & .03 & .13 \\
\hline Openness & 3.49 & .55 & .056 & .091 & .06 & .145 & $.19^{*}$ & .16 & .01 \\
\hline
\end{tabular}

${ }^{\mathrm{a}} \mathrm{N}=76$

$*_{p}<0.05$

$* * \mathrm{p}<.01$. 